\title{
Speeds Criteria vs. Modified Aldrete and Fast-Track Criteria for Evaluating Recovery in Outpatients
}

\author{
Brent Burke ${ }^{1}$, Mark Kyker ${ }^{2}$ \\ ${ }^{1}$ Indiana Surgery Center East, Indianapolis, USA; ${ }^{2}$ St. Vincent Health, Carmel, USA. \\ Email: mkyker@gmail.com \\ Received April 13 ${ }^{\text {th }}, 2013$; revised May 15 ${ }^{\text {th }}, 2013$; accepted June $10^{\text {th }}, 2013$ \\ Copyright (C) 2013 Brent Burke, Mark Kyker. This is an open access article distributed under the Creative Commons Attribution \\ License, which permits unrestricted use, distribution, and reproduction in any medium, provided the original work is properly cited.
}

\begin{abstract}
Background: The authors have developed criteria utilizing the mnemonic "SPEEDS" (saturation, pain, extremity movement, emesis, dialogue, stable vitals signs) to evaluate and predict which patients would not require phase I nursing intervention and could transition to phase II recovery. Methods: Seventy-three adult surgery patients underwent a standardized general anesthetic. Patients were evaluated with the modified Aldrete, Fast-Track and SPEEDS criteria immediately before leaving the OR and then 5, 10, 15 and 30 minutes after arrival in the recovery area. Results: Significantly more patients met phase I bypass criteria when evaluated with Modified Aldrete (90\%) and Fast-Track (94\%) as compared to SPEEDS (77\%) ( $\mathrm{p}<0.0429$ modified Aldrete vs. SPEEDS, $\mathrm{p}<0.0038$ Fast-Track vs. SPEEDS). However, SPEEDS was more sensitive having a lower number of patients meeting phase II criteria yet requiring phase I intervention (32\%) vs. Fast-track (43\%) and Modified Aldrete (44\%) $(\mathrm{p}<0.001$ SPEEDS vs. modified Aldrete and Fast-Track). SPEEDS was more accurate (74\%) in predicting which patients should move directly to phase II compared to modified Aldrete $(42 \%)(\mathrm{p}<0.001)$ and Fast-track $(59 \%)(\mathrm{p}=0.05)$. Conclusion: SPEEDS criteria are as specific and more sensitive in determining phase I nursing interventions for ambulatory surgery patients when compared to Fast-Track and modified Aldrete criteria.
\end{abstract}

Keywords: Phase I Bypass; Fast Track; PACU Nursing Interventions

\section{Introduction}

With the advent of fast-track anesthesia, the elimination of the traditional recovery room has become possible [1]. In fact, our ambulatory surgery center has incorporated this type of design. However, in most traditional OR suites, a phase I recovery area and a step-down or phase II recovery exist in separate locations. In order to bypass phase I recovery, surgical patients must be assessed in the operating room immediately upon awakening and determination is made concerning the suitability of bypass. An efficient assessment tool is needed to allow for a rapid decision as to whether a patient is able to progress to phase II and not require phase I type nursing care. The modified Aldrete criteria [2] have been the traditional method of evaluating patients for discharge to the surgical ward or phase II recovery for outpatients. Recently, White and Song proposed a fast-track scoring system [3] that incorporates not only the modified Aldrete criteria but also an assessment of pain and nausea both of which are typically treated in phase I recovery.
We have developed new, simplified criteria for evaluating surgical patients recovering from general anesthesia that is easily applied and utilizes the mnemonic "SPEEDS". This stands for oxygen saturation, pain control, emesis control, extremity movement, dialogue, and stable vital signs. Instead of using a point system, the SPEEDS criteria require a simple "yes" or "no" response to each parameter. A patient must have a response of "yes" to all parameters to progress to phase II recovery (Appendix 1). We compared the new SPEEDS criteria to both the modified Aldrete and the Fast-Track system in an ambulatory surgery center where fast tracking is emphasized. We hypothesized that SPEEDS criteria would be as good as or better than existing scoring systems at predicting which patients would require phase I nursing interventions.

\section{Methods}

After obtaining institutional review board approval and written informed consent from all patients, recovery data 
was obtained from 73 adult outpatients selected from the general population undergoing a wide range of surgical procedures from April 2001 to July 2001. Exclusion criteria included a pre-operative visual analogue pain score greater than 4 or oxygen saturation less than $95 \%$ on room air.

All patients were premedicated with Rofecoxib $50 \mathrm{mg}$ and Acetomenophen $1000 \mathrm{mg}$ p.o. before induction with propofol (1.5 - $2.0 \mathrm{mg} / \mathrm{kg})$, fentanyl (1 - $1.5 \mathrm{ug} / \mathrm{kg})$ and succinylcholine $(1 \mathrm{mg} / \mathrm{kg})$ to facilitate intubation if necessary and then maintained with desflurane, nitrous oxide, and oxygen titrated to a BIS of 40 - 50. Droperidol $(0.625 \mathrm{mg})$ and dexamethasone $(10 \mathrm{mg}) \mathrm{IV}$ were given for anti-emetic prophylaxis. Local anesthetic infiltration was provided with levobupivacaine $1 \%$. Neuromuscular blockade was obtained with mivacurium (2 - $4 \mathrm{mg}$ ) IV as needed to maintain TOF ratio less than 0.2. Morphine (up to $0.1 \mathrm{mg} / \mathrm{kg}$ ) IV was given at the discretion of the anesthesiologist for post-op analgesia. Also, Fentanyl $50 \mathrm{ug}$ IV (up to $250 \mathrm{ug}$ ) or labetolol 5mg IV (up to $20 \mathrm{mg}$ ) was given to control noxious and /or hyperdynamic responses as deemed necessary. Patients were evaluated with the modified Aldrete, Fast-Track and SPEEDS criteria immediately before leaving the OR by the anesthesiologist and then by the PACU nurse in the post-surgical suite at 5, 10, 15 and 30 minutes post arrival. All patients were transferred directly to the step-down suite as our facility was designed without a phase I recovery area. Phase I interventions (defined as intravenous administration of analgesics, antiemetics, antihypertensives and/or the administration of oxygen therapy) could be given if necessary at that location by a recovery nurse in the pre/postop suite.

In evaluating the SPEEDS criteria, a visual analogue scale (VAS) score of less than 4 was considered a "yes" response for pain control. Systolic blood pressure in the range of 90 - $180 \mathrm{~mm}$ and a heart rate in the range of 50 $110 \mathrm{bpm}$ was necessary to be considered hemodynamically stable and receive a "yes" response for stable vital signs. An oxygen saturation greater than 90 on room air was considered adequate for oxygen saturation. Patients were considered fast-track eligible if they achieved a modified Aldrete score of greater than or equal to 9, a Fast-Track score of greater than or equal to 12 (with no score less than 1 in any individual category) or an all "yes" response to the SPEEDS criteria. Individual types of post-op nursing interventions (e.g. IV analgesics, IV anti-emetics) were recorded along with discharge times and any post-op complications.

\section{Data Analysis Methods}

To summarize the validity and reliability of each of the screening tests, seven measures were used including, sensitivity, false positive rate, specificity, false negative rate, positive predictive value, negative predictive value and accuracy were calculated relative to nurse intervention [4]. The positive predictive value is the probability that a patient requires phase I nursing intervention, if that patient tests positive (does not meet phase I bypass criteria). Likewise, the negative predictive value is the probability that a patient does not require phase I nursing intervention, given that patient tests negative (does meet phase I bypass criteria). Accuracy is the proportion of all correct tests.

The method used to calculate the confidence interval for a proportion is the Wilson score method without continuity correction [5]. It is a refinement of the simple asymptotic method, and computationally much simpler than the method of Clopper and Pearson [6] since closedform solutions for lower and upper limits are available, both without and with [7] continuity correction. It has the theoretical advantage among asymptotic methods of being derived from the "efficient score" approach [8]. Newcombe [9] shows that Wilson score confidence intervals have logit scale symmetry property with consequent log scale symmetry for certain derived intervals.

To test that the effect of several time points among the three scales logistic regression was used. In this model, time was used as a continuous independent variable and scale was categorical.

To examine the overall performance between two screening tests, each patient was classified according to the result of their post-operative screening tests. There were two possible agreeing-classifications and two crossclassifications. For example, to assess the performance of SPEEDS relative to the modified Aldrete, patients were classified as, failed-failed, passed-failed, failed-passed, and passed-passed, respectively. The two middle groups were identified as the cross-classifications. The odds of requiring nurse intervention can be calculated for each of the four classifications.

If the two screening tests were similar then the odds for the cross-classification groups would be near one. To evaluate performance, we can compare the odds of the cross-classifications. We fit a generalized linear model [10] to the data by the method of maximum likelihood estimation, using a logit link function and binomial variance structure. The independent variable was the scoring test classification and the dependent variable was nurse intervention. The contrast between cross-classifications was tested using the Wald statistic.

\section{Results}

The patient demographic data and distribution of case type show a wide range of ages and procedures in a community setting (Table 1).

Phase I bypass rates were significantly higher with Fast-Track (95.4\%) and modified Aldrete (90.4\%) crite- 
Table 1. Demographics.

\begin{tabular}{|c|c|c|}
\hline$\underline{\text { Demographic }}$ & & $(\mathrm{N}=73)$ \\
\hline Women (\%) & & 53.4 \\
\hline Men (\%) & & 46.6 \\
\hline Age (years) & & $47 \pm 17$ \\
\hline Weight (kilograms) & & $82 \pm 20$ \\
\hline \multirow[t]{4}{*}{ ASA Physical Status (\%) } & I & $31.5 \%(23)$ \\
\hline & II & $48.5 \%(35)$ \\
\hline & III & $17.8 \%(13)$ \\
\hline & IV & $2.7 \%(2)$ \\
\hline Case Types & & \# of Patients \\
\hline ENT & & 10 \\
\hline General Surgery & & 4 \\
\hline GU & & 11 \\
\hline Hysteroscopy & & 1 \\
\hline Inguinal Hernia & & 3 \\
\hline Laparoscopic & & 13 \\
\hline Lumbar Disc & & 4 \\
\hline Peripheral Extremity & & 25 \\
\hline Shoulder Surgery & & 2 \\
\hline
\end{tabular}

ria compared to SPEEDS (76.7\%) ( $\mathrm{p}<0.0429$ modified Aldrete vs. SPEEDS and $\mathrm{p}<0.0038$ Fast-Track vs. SPEEDS). Longitudinal analysis showed a statistically significant difference in bypass rates between Fast-Track and modified Aldrete criteria vs. SPEEDS criteria at 5, 10, 15 and 30 minutes post-op (Table 2). Significantly more bypass eligible patients required phase I interventions with both modified Aldrete and Fast-Track criteria vs. SPEEDS (Figure 1).

Table 3 provides performance summaries for the three post-operative screening tests. SPEEDS provided a statistically significantly greater sensitivity when compared to modified Aldrete and Fast-Track. All three screening tests were highly specific in identifying patients who would require nurse intervention. The positive predictive value for all three screening tests was adequate; however the accuracy of SPEEDS was statistically significantly greater than that of either modified Aldrete or FastTrack.

The overall performance of each screening test as measured by the difference in the odds for correctly predicting nurse intervention was statistically significantly

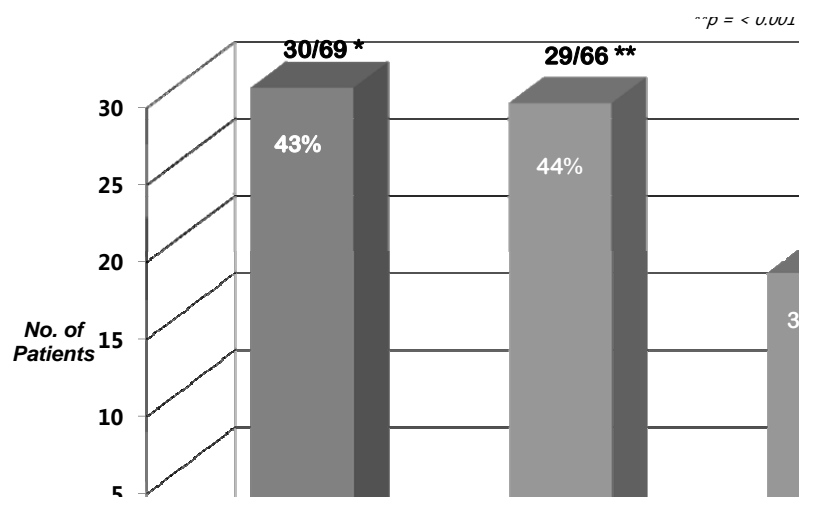

Figure 1. Bypassed patients needing intervention. " $p \leq 0.001$ — Speeds vs. Fast-Track; ${ }^{* *} \mathbf{p} \leq \mathbf{0 . 0 0 1}-$ Speeds vs. Modified Aldrete.

Table 2. Bypass rates during $1^{\text {st }} \mathbf{3 0}$ minutes recovery $(\mathrm{n}=7$ 3).

\begin{tabular}{cccccc}
\hline & $\begin{array}{c}\mathbf{0} \\
\text { minutes }\end{array}$ & $\begin{array}{c}\mathbf{5} \\
\text { minutes }\end{array}$ & $\begin{array}{c}\mathbf{1 0} \\
\text { minutes }\end{array}$ & $\begin{array}{c}\mathbf{1 5} \\
\text { minutes }\end{array}$ & $\begin{array}{c}\mathbf{3 0} \\
\text { minutes }\end{array}$ \\
\hline Speeds & $56(77 \%)$ & $53(73 \%)$ & $54(74 \%)$ & $56(77 \%)$ & $59(81 \%)$ \\
Fast-Track & $69(94 \%)$ & $68(93 \%)$ & $69(94 \%)$ & $69(94 \%)$ & $69(94 \%)$ \\
Modified Aldrete $66(90 \%)$ & $62(85 \%)$ & $65(89 \%)$ & $65(89 \%)$ & $67(92 \%)$ \\
\hline $\begin{array}{l}\text { p < 0.01. Speeds vs. fast-track \& modified Aldrete at } 0,5,10,15, \& 30 \\
\text { minutes. }\end{array}$
\end{tabular}

greater for SPEEDS when compared to the modified Aldrete (Table 4).

The majority of phase 1 interventions in bypass eligible patients were for IV analgesia, the second most common being IV antiemetics (Figure 2). Note some individual patients required more than one type of intervention, e.g. both IV analgesics and anti-emetics.

Post-operative nausea and vomiting incidence was 9.6\% (7/73). Average case duration was 65 minutes with a standard deviation of 39.4 minutes. Average time from anesthetic discontinuation to PACU arrival was 6.6 minutes with a standard deviation of 1.7 minutes. Average discharge time was 137 minutes with a standard deviation of 85.4 minutes. One patient $(1.3 \%)$ required a return to the emergency room for post-operative urinary retention.

\section{Discussion}

In the present cost-conscious healthcare environment, the use of fast tracking can have favorable financial implications for a hospital or ambulatory surgery center because rapid discharge can reduce the cost of care. Macario [11] showed that a decrease in OR and recovery times have a greater economic impact than that achieved by reducing anesthesia drug costs alone. Fast-track anesthesia in outpatient care has been associated with substantial costsavings with no change in patient outcomes [12]. At 5 


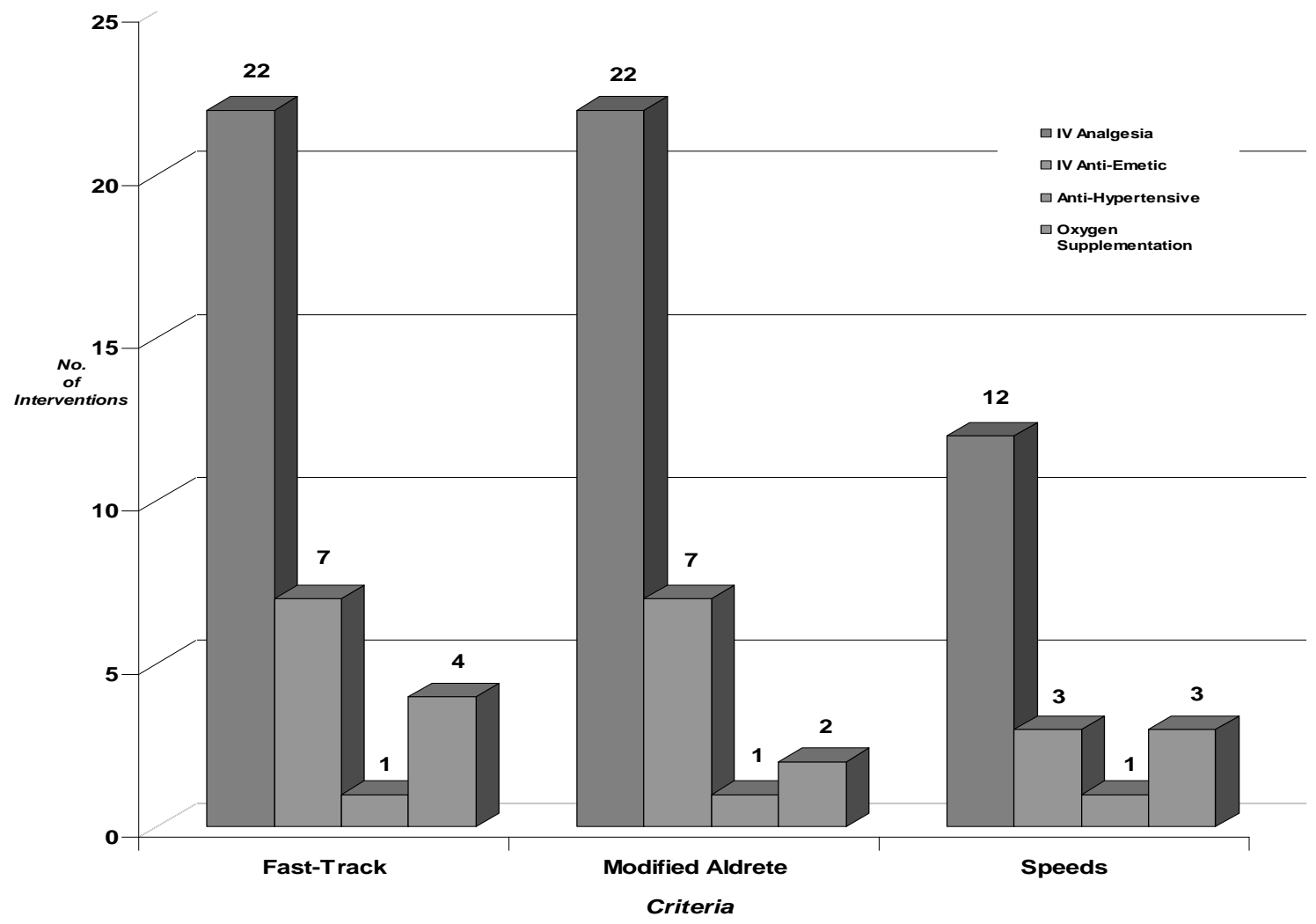

Figure 2. Types of intervention bypassed patients.

Table 3. Validation statistics (and $95 \%$ confidence intervals) for three post-operative screening tests predicting nurse intervention in 73 patients.

\begin{tabular}{cccccc}
\hline & SPEEDS (SPD) & Modified Aldrete (MA) & Fast-Track (FT) & SPD vs. MA & SPD vs. FT \\
\hline Sensitivity & $47.06(31.45,63.26)$ & $14.71(6.45,30.13)$ & $11.76(4.67,26.62)$ & $\mathrm{p}<0.001$ & $\mathrm{p}<0.001$ \\
False Positive Rate & $52.94(36.74,68.55)$ & $85.29(69.87,93.55)$ & $88.24(73.38,95.33)$ & $\mathrm{p}<0.001$ & $\mathrm{p}<0.001$ \\
Specificity & $97.44(86.82,99.55)$ & $94.87(83.11,98.58)$ & $100.00(91.03,100.00)$ & $\mathrm{p}=0.478$ & $\mathrm{p}=0.361$ \\
False Negative Rate & $2.56(0.45,13.18)$ & $5.13(1.42,16.89)$ & $0.00(0.00,8.97)$ & $\mathrm{p}=0.478$ & $\mathrm{p}=0.361$ \\
Positive Predictive Value & $94.12(73.02,98.95)$ & $71.43(35.89,91.78)$ & $100.00(51.01,100.00)$ & $\mathrm{p}=0.015$ & $\mathrm{p}=0.453$ \\
Negative Predictive Value & $67.86(54.82,78.60)$ & $56.06(44.08,67.37)$ & $56.52(44.79,67.57)$ & $\mathrm{p}=0.049$ & $\mathrm{p}=0.056$ \\
Accuracy & $73.97(62.89,82.66)$ & $42.47(31.78,53.90)$ & $58.90(47.45,69.47)$ & $\mathrm{p}<0.001$ & $\mathrm{p}=0.005$ \\
\hline
\end{tabular}

Table 4. Performance odds of post-operative screening compared with SPEEDS relative to accurately predicting nurse intervention.

\begin{tabular}{ccccc}
\hline Prognostic Test & Odds of NI for Pass-Fail Group & Odds of NI for Fail-Pass Group & Wald Statistic & p-Value \\
\hline Modified Aldrete & 12.00 & 0.50 & 3.91 & 0.048 \\
Fast Track & 12.00 & n/a & 8.97 & 0.003 \\
\hline
\end{tabular}

institutions, annualized savings of $\$ 50,000$ to $\$ 160,000$ per year were realized when phase I bypass rates of $14 \%$ - $42 \%$ were achieved [12]. For many of the above reasons we incorporated an aggressive fast track program at our surgery center. In refining our techniques, we felt a simplified bypass criteria could be established as compared to the criteria presently available. White and Song showed that Fast-Track criteria offered advantages over modified Aldrete for determining phase I bypass [3] However, we felt Fast-Track criteria were too cumbersome as well as lenient. For example, currently accepted criteria require calculating deviations from preoperative hemodynamic parameters as well as allow a patient to experience transient emesis and pain requiring intravenous analgesia yet still meeting fast track criteria. It should be noted the authors of Fast-Track criteria did 
suggest further validation [3]. The current study was our initial attempt to see if SPEEDS could predict which patients would not require phase I nursing treatment and could proceed to phase II with confidence, thereby facilitating our fast track program.

In analyzing our data, we defined a positive test as being able to determine those patients who required phase I nursing interventions. A very sensitive test would have a low "false negative" rate or in this case, a low rate of bypass for those who subsequently required phase I nursing interventions. A very specific test would have a low "false positive" rate or in this case, a low number of patients who did not meet bypass criteria but did not require phase I nursing intervention post-op. All three tests were specific in identifying patients that required phase I nursing interventions post-operative. With SPEEDS criteria, significantly more patients were correctly identified as eligible for bypass. Only 32\% of SPEEDS eligible patients needed a phase I intervention compared to $44 \%$ with Fast-Track criteria and 43\% with modified Aldrete ( $\mathrm{p}<0.001$ vs. both Fast-Track and modified Aldrete). In other words, when SPEEDS determined a patient could move to phase II, the clinician is more assured that the patient will not require phase I intervention. Also the accuracy of SPEEDS was significantly greater than either Fast-Track $(74.0 \%$ vs. $58.9 \%$; $p=00.005$ or modified Aldrete (74.0\% vs. 42.5\%; p < 0.0001). This may help an institution in determining nurse to patient ratios.

Longitudinal analysis revealed statistically significant differences in bypass rates at all times studied. SPEEDS ineligible patients continued to not meet requirements because of the need for phase I interventions; whereas, the majority of these patients met criteria via the other two methods over the first 30 minutes of recovery. SPEEDS continued to be more sensitive and could be used as criteria in the PACU for transition from phase I to phase II.

The majority of phase I interventions in bypass eligible patients were for IV analgesia with all 3 criteria. This data support Pavlin's [13] findings that improvements in pain therapy are needed to expedite recovery. Although not specifically addressed in this study, surgical invasiveness seemed to correlate with suitability for bypass. More invasive and hence painful procedures tended to require more nursing intervention for post-operative analgesia and this need should be anticipated when implementing bypass strategies [14]. The second most common intervention in bypassed patients was for IV antiemetic therapy. Similarly, anti-emetic prophylaxis for patients at risk is a logical part of bypass strategies [14]. Opportunities exist for further study into the impact of various pain management and anti-emetic modalities on successful phase I bypass.

Readers may question whether our technique is to just wait until the patient is ready for phase II, however; this was not the case as our average time from discontinuing the agent until arriving in the PACU was 6.6 minutes. Some may question the value of utilizing bypass criteria in a facility without a traditional recovery area. We have found that SPEEDS criteria give a better idea as to which patients are more likely to need phase I intervention and thus require higher nursing acuity and feel this could be used quite effectively in a traditional set up as well.

Although the accuracy of SPEEDS is significantly better than the other criteria, a fairly large percent of patients are bypassed and eventually need Phase I intervention. In part, this finding is a reflection of the dynamic, changing nature of post-operative recovery. What seems to be an adequate recovery can quickly change because of motion-induced nausea and vomiting or the unmasking of pain following the elimination of residual anesthesia. Due to the interpatient variability in analgesic requirements, it is difficult to predict which bypassed patients will require phase I nursing intervention and subsequently relapse. Further efforts to control and eliminate these issues are warranted.

In developing the SPEEDS criteria, one goal was a user-friendly mnemonic. We felt that using extremity movement to command would be an adequate substitute for the standard 5 second head lift. Our goal is to have the patient move to the gurney without assistance upon completion of the surgery. Although the range of vital signs may seem arbitrary, their utilization did not affect patient outcomes. Perhaps, if a clinician is uncomfortable with these values, then they could substitute their own values accordingly.

This study could be criticized for the relatively small number of patients, although statistically viable. Also, our surgery center is atypical in its layout, although we feel it is an advantage in our practice. Lastly, we only carried out the evaluation for 30 minutes which often is not enough time to adequately control pain or nausea in certain cases (e.g., laparoscopic cholecystectomy).

In summary, the authors examined the use of an easily applied mnemonic for evaluating fast track recovery in outpatients following general anesthesia. The SPEEDS criteria are self-explanatory and require a yes/no response without calculations for deviations from pre-operative blood pressure. SPEEDS criteria are significantly more sensitive and accurate in identifying patients who will require phase I nursing interventions. Therefore, it appears SPEEDS has advantages over Fast-Track Scoring System and modified Aldrete criteria in evaluating suitability for phase I recovery bypass following general anesthesia.

\section{REFERENCES}

[1] D. A. Lubarsky, "Fast Track in the Post-Anesthesia Care Unit: Unlimited Possibilities?” Journal of Clinical Anesthesia, Vol. 8, No. 3, 1996, pp. 70S-72S. 
doi:10.1016/S0952-8180(96)90016-1

[2] J. A. Aldrete, "The Post-Anesthesia Score Revisited," Journal of Clinical Anesthesia, Vol. 7, No. 1, 1995, pp. 89-91. doi:10.1016/0952-8180(94)00001-K

[3] P. F. White, "Criteria for Fast-Tracking Outpatients after Ambulatory Surgery,” Journal of Clinical Anesthesia, Vol. 90, No. 6, 1999, pp. 1178-1190.

[4] T. Greenhalgh, "How to Read a Paper: Papers That Report Diagnostic or Screening Tests,” BMJ, Vol. 315, No. 7107, 1997, pp. 540-543.

[5] E. B. Wilson, "Probable Inference, the Law of Succession, and Statistical Inference," Journal of the American Statistical Association, Vol. 22, No. 158, 1927, pp. 209-212. doi:10.1080/01621459.1927.10502953

[6] C. J. Clopper and E. S. Pearson, "The Use of Confidence or Fiducial Limits Illustrated in the Case of the Bino- mial,” Biometrika, Vol. 26, No. 4, 1934, pp. 404-413.

[7] J. L. Fleiss, "Statistical Methods for Rates and Proportions," 2nd Edition, Wiley, New York, 1981.

[8] D. R. Cox and D. V. Hinkley, "Theoretical Statistics," Chapman and Hall, London, 1974. doi:10.1007/978-1-4899-2887-0

[9] R. G. Newcombe, "Two-Sided Confidence Intervals for the Single Proportion: Comparison of Seven Methods," Statistics in Medicine, Vol. 17, No. 8, 1998, pp. 857-872.
doi:10.1002/(SICI)1097-0258(19980430)17:8<857::AID$\underline{\mathrm{SIM} 777>3.0 . \mathrm{CO} ; 2-\mathrm{E}}$

[10] J. F. Nelder and R. W. M. Wedderburn, "Generalized Linear Models,” Journal of the Royal Statistical Society A, Vol. 135, No. 3, 1972, pp. 370-384.

[11] A. Macario, T. Vitez, B. A. Dunn and T. McDonald, "Where Are the Costs in Perioperative Care? Analysis of Hospital Costs and Charges for Inpatient Surgical Care," Anesthesiology, Vol. 83, No. 6, 1995, pp. 1138-1144. doi:10.1097/00000542-199512000-00002

[12] J. L. Apfelbaum, C. A. Walawander and the SAFE Study Team, "Eliminating Intensive Postoperative Care in SameDay Surgery Patients Using Short-Acting Anesthetics," Anesthesiology, Vol. 97, No. 1, 2002, pp. 66-74. doi:10.1097/00000542-200207000-00010

[13] D. Pavlin, C. Chen and D. Penaloza, "Pain as a Factory Complicating Recovery and Discharge after Ambulatory Surgery,” Anesthesia \& Analgesia, Vol. 95, No. 3, 2002, pp. 627-634.

[14] B. A. Williams, M. L. Kentor and J. P. Williams, "PACU Bypass after Outpatient Knee Surgery Is Associated with Fewer Unplanned Hospital Admissions But More Phase 2 Nursing Interventions,” Anesthesiology, Vol. 97, No. 4, 2002, pp. 981-988. doi:10.1097/00000542-200210000-00034

\section{Appendix 1}

\begin{tabular}{|c|c|c|c|c|c|}
\hline fast-track criteria $^{* *}$ & score & modified aldrete criteria & score & speeds criteria & score \\
\hline $\begin{array}{l}\text { Level of consciousness } \\
\text { 1. Awake \& orientated } \\
\text { 2. Arousable w/minimal stimulation } \\
\text { 3. }\end{array}$ & $\begin{array}{l}2 \\
1 \\
\mathbf{0}\end{array}$ & $\begin{array}{l}\text { Activity } \\
\text { 1. } \\
\text { 2. Moves all extremities } \\
\text { 3. } \quad \text { Unoves two extremities } \\
\text { Unable to move extremities }\end{array}$ & $\begin{array}{l}2 \\
\mathbf{1} \\
\mathbf{0}\end{array}$ & $\begin{array}{c}\text { Oxygen } \\
\frac{\text { saturation }}{\text { room air }}\end{array}$ & $\mathbf{Y} / \mathbf{N}$ \\
\hline $\begin{array}{l}\text { Physical activity } \\
\text { Able to move all extremities on command } \\
\text { Some weakness in movement of extremities } \\
\text { Unable to voluntarily move extremities }\end{array}$ & $\begin{array}{l}2 \\
1 \\
\mathbf{0}\end{array}$ & $\begin{array}{l}\text { Respiration } \\
\text { 1. Breathes deeply, coughs freely } \\
\text { 2. Dyspenic, shallow or limited breathing } \\
\text { 3. Apneic }\end{array}$ & $\begin{array}{l}2 \\
1 \\
0\end{array}$ & $\frac{\text { Pain Control }}{(\text { vas }<4)}$ & $\mathbf{Y} / \mathbf{N}$ \\
\hline $\begin{array}{c}\text { Hemodynamic stability } \\
(\text { MAP }=\text { Mean arterial pressure }) \\
\text { 1. } \quad \text { Blood pressure }<15 \% \text { of baseline MAP value } \\
\text { 2. Blood pressure } 15-30 \% \text { of baseline MAP value } \\
\text { 3. } \quad \text { Blood pressure }>30 \% \text { below baseline MAP value }\end{array}$ & $\begin{array}{l}2 \\
1 \\
\mathbf{0}\end{array}$ & $\begin{array}{l}\text { Circulation (blood pressure) } \\
\text { 1. } \quad 20 \mathrm{~mm} \mathrm{Hg}>\text { preanesthetic level } \\
\text { 2. } 20-50 \mathrm{~mm} \mathrm{Hg}>\text { preanesthetic level } \\
\text { 3. } 50 \mathrm{~mm} \mathrm{Hg}>\text { preanesthetic level }\end{array}$ & $\begin{array}{l}2 \\
1 \\
\mathbf{0}\end{array}$ & $\begin{array}{c}\text { Extremity } \\
\text { movement } \\
\text { (moves all four) }\end{array}$ & $\mathbf{Y} / \mathbf{N}$ \\
\hline $\begin{array}{l}\text { Respiratory stability } \\
\text { 1. Able to breathe deeply } \\
\text { 2. Tachypnea with good cough } \\
\text { 3. Dyspneic with weak cough }\end{array}$ & $\begin{array}{l}\mathbf{2} \\
\mathbf{1} \\
\mathbf{0}\end{array}$ & $\begin{array}{l}\text { Consciousness } \\
\text { 1. } \\
\text { 2. } \\
\text { 2. Arousable on calling } \\
\text { 3. Not responding }\end{array}$ & $\begin{array}{l}2 \\
1 \\
\mathbf{0}\end{array}$ & $\underline{\text { Emesis }}$ Control & $\mathbf{Y} / \mathbf{N}$ \\
\hline $\begin{array}{l}\text { Oxygen saturation status } \\
\text { 1. Maintains value }>90 \% \text { on room air } \\
\text { 2. Requires supplemental oxygen (nasal prongs) } \\
\text { 3. Saturation }<90 \% \mathrm{w} /=\text { supplemental oxygen }\end{array}$ & $\begin{array}{l}2 \\
1 \\
\mathbf{0}\end{array}$ & $\begin{array}{l}\quad \text { Oxygen saturation } \\
\text { 1. } \mathrm{SpO}_{2}>92 \% \text { on room air } \\
\text { 2. Supplemental } \mathrm{O}_{2} \text { required to maintain } \\
\mathrm{SpO}_{2}>90 \% \\
\text { 3. } \mathrm{SpO}_{2}<90 \% \mathrm{w} / \mathrm{O}_{2} \text { supplementation }\end{array}$ & $\begin{array}{l}2 \\
1 \\
0\end{array}$ & $\begin{array}{c}\frac{\text { Dialogue }}{\text { (oriented }} \\
\text { person/place) }\end{array}$ & $\mathbf{Y} / \mathbf{N}$ \\
\hline $\begin{array}{l}\text { Postoperative pain assessment } \\
\text { 1. None or mild discomfort } \\
\text { 2. Moderate to severe pain controlled w/IV analgesics } \\
\text { 3. Persistent severe pain }\end{array}$ & $\begin{array}{l}2 \\
1 \\
\mathbf{0}\end{array}$ & & & $\begin{array}{c}\text { Stable vital signs } \\
S B P>90 \text { and }<180 \\
H R>50 \text { and }<110\end{array}$ & $\mathbf{Y} / \mathbf{N}$ \\
\hline $\begin{array}{l}\text { Postoperative emetic symptoms } \\
\text { 1. None or mild nausea w/no active vomiting } \\
\text { 2. Transient vomiting or retching } \\
\text { 3. Persistent moderate to severe nausea \& vomiting }\end{array}$ & $\begin{array}{l}2 \\
1 \\
\mathbf{0}\end{array}$ & & & & \\
\hline
\end{tabular}

*A minimal score of 12 (with no score $<1$ in any individual category) would be required for a patient after general anesthesia. ${ }^{\#}$ A score of 9 or less would be required for a patient after general anesthesia for discharge. ${ }^{* *}$ Anesth and Analg, 1999; 8:1072; ${ }^{\# \#}$ Contemporary Surgery, Nov. 2000 ; Vol 56, No.11. 